\title{
2,4-Diacetylphloroglucinol Alters Plant Root Development
}

\author{
Jessica N. Brazelton, ${ }^{1}$ Emily E. Pfeufer, ${ }^{1}$ Teresa A. Sweat, ${ }^{2}$ Brian B. McSpadden Gardener, ${ }^{3}$ and \\ Catharina Coenen ${ }^{1}$
}

${ }^{1}$ Biology Department, Allegheny College, 520 N Main Street, Meadville, PA 16335, U.S.A.; ${ }^{2}$ United States Department of Agriculture-Agricultural Research Service, Horticultural Crops Research Laboratory, 3420 NW Orchard Avenue, Corvallis, OR 97330-5014, U.S.A.; ${ }^{3}$ Department of Plant Pathology, The Ohio State University-OARDC, 1680 Madison Avenue, Wooster, $\mathrm{OH} 44691$, U.S.A.

Submitted 4 February 2008. Accepted 18 June 2008.

\begin{abstract}
Pseudomonas fluorescens isolates containing the phlD gene can protect crops from root pathogens, at least in part through production of the antibiotic 2,4-diacetylphloroglucinol (DAPG). However, the action mechanisms of DAPG are not fully understood, and effects of this antibiotic on host root systems have not been characterized in detail. DAPG inhibited primary root growth and stimulated lateral root production in tomato seedlings. Roots of the auxin-resistant diageotropica mutant of tomato demonstrated reduced DAPG sensitivity with regards to inhibition of primary root growth and induction of root branching. Additionally, applications of exogenous DAPG, at concentrations previously found in the rhizosphere of plants inoculated with DAPGproducing pseudomonads, inhibited the activation of an auxin-inducible $\mathrm{GH} 3$ promoter::luciferase reporter gene construct in transgenic tobacco hypocotyls. In this model system, supernatants of 17 phlD $+P$. fluorescens isolates had inhibitory effects on luciferase activity similar to synthetic DAPG. In addition, a phlD ${ }^{-}$mutant strain, unable to produce DAPG, demonstrated delayed inhibitory effects compared with the parent wild-type strain. These results indicate that DAPG can alter crop root architecture by interacting with an auxin-dependent signaling pathway.
\end{abstract}

Some strains of Pseudomonas fluorescens, a bacterium native to soils around the world, inhibit the growth of diverse pathogens that cause soilborne crop diseases such as damping off, root rot, take-all, and other wilting diseases (McSpadden Gardener 2007). The biocontrol activity of many P. fluorescens isolates has been linked to production of the secondary metabolite 2,4-diacetylphloroglucinol (DAPG) (Dwivedi and Johri 2003; Weller et al. 2002). Although DAPG exhibits clear antifungal activity (Keel et al. 1992), the effects of this compound on roots remain largely unknown.

DAPG toxicity to a broad spectrum of organisms, such as bacteria, fungi, protists, and nematodes, suggests that its targets may include basic cellular processes. In the fungus $P y$ thium ultimatum var. sporangiiferum, DAPG causes alterations of the plasma membrane, vacuolization, and the disintegration of cell contents (de Souza et al. 2003), suggesting that it impedes the maintenance of membrane integrity. In bacteria, DAPG may cause lysis by a novel antibiotic mechanism. For

Corresponding author: C. Coenen; E-mail: catharina.coenen@allegheny.edu; Telephone: +1.814 .332 .2703 .

* The $e$-Xtra logo stands for "electronic extra" and indicates that a supplemental figure is published online. instance, methicillin-resistant Staphylococcus aureus will lyse within $2 \mathrm{~h}$ of exposure to $5 \mu \mathrm{M}$ DAPG, whereas Vibrio parahaemolyticus lyses more slowly and in response to higher DAPG concentrations of $114 \mu \mathrm{M}$ (Kamei and Isnansetyo 2003). Differential DAPG sensitivity of these gram-positive and gramnegative bacteria suggests that the structure of the cell wall may influence DAPG uptake or responsiveness. Interestingly, exogenously supplied DAPG-containing supernatants are nontoxic to phagotrophic protists such as the ciliate Colpoda steinii and the flagellate Neobodo designis, although ingestion of DAPG-producing Pseudomonas strains rapidly poisons these organisms (Jousset et al. 2006). By contrast, the osmotrophic amoeba Vahlkampfia sp. exhibits cell lysis within $1 \mathrm{~h}$ of DAPG exposure, with loss of motility occurring within minutes (Jousset et al. 2006), suggesting that DAPG sensitivity of protists is also determined by DAPG permeability of the cell surface. Despite its stability under temperature and $\mathrm{pH}$ conditions found in the mammalian digestive tract, DAPG at up to $100 \mathrm{mg} / \mathrm{kg}$ surprisingly fails to elicit acute toxicity in mice (Kamei and Isnansetyo 2003).

DAPG inhibits growth and seed germination in a variety of crop plants (Keel et al. 1992; Maurhofer et al. 1995), but the mechanisms underlying these effects are not understood. Increased root mass and lateral root formation of pea plants inoculated with DAPG-producing Pseudomonas fluorescens, compared with a non-DAPG-producing mutant, led to the suggestion that DAPG may act as a plant-hormone-like substance (De Leij et al. 2002), and the specificity of DAPG effects for broad-leaf species can resemble that of the auxin-herbicide 2,4-dichlorophenonxyacetic acid (2,4-D) (Reddi et al. 1969). However, to our knowledge, potential interactions between DAPG and auxin signaling have not been examined. A DAPGinduced blocking of amino acid uptake by alfalfa roots has been hypothesized to be linked to an inhibition of proton secretion across the plasma membrane (Phillips et al. 2004), which is also an auxin-like effect (Coenen et al. 2002). However, effects of DAPG on root proton secretion have not been investigated directly.

Some DAPG-producing Pseudomonas strains change host root length or induce the formation of supernumerary lateral roots (Dubeikovsky et al. 1993; Patten and Glick 2002; Suzuki et al. 2003). Although this alteration in host root physiology has been attributed to the bacteria producing the plant hormone auxin, indole-3-acetic acid (IAA) (Dubeikovsky et al. 1993), the role of IAA as the sole agonist of changes in root architecture in the presence of $P$. fluorescens has not yet been determined conclusively. Because the growth media used in experiments demonstrating IAA synthesis by $P$. fluorescens in vitro commonly contain high concentrations of the IAA precursor 
tryptophan (Oberhänsli et al. 1991; Patten and Glick 2002; Suzuki et al. 2003), it is unclear whether such rhizosphere bacteria typically produce sufficient amounts of IAA in situ to elicit root morphology changes. At least one non-auxin-volatile compound, 2R,3R,butanediol, secreted by P. chlororaphis O6, can promote host plant growth (Han et al. 2006), and volatiles produced by Bacillus subtilis GB03 promote growth through enhancing auxin synthesis and transport in Arabidopsis (Zhang et al. 2007). The effects of nonauxin secreted $P$. fluorescens products such as DAPG on auxin response pathways have not been previously investigated.

Auxin exerts its effects on plant cells by upregulating transcription of a wide variety of genes. Activation of auxin-induced genes occurs within minutes (McClure and Guilfoyle 1987) and is mediated by auxin binding to a soluble, intracellular receptor protein, $\mathrm{SCF}^{\mathrm{TIR} 1}$ (Dharmasiri et al. 2005a; Kepinski and Leyser 2005), or to one of its homologs (Dharmasiri et al. 2005b). Auxin binding allows these receptor proteins to bind transcriptional repressor proteins of the AUX/IAA protein family and target them for degradation through the 26S proteasome pathway (Gray et al. 2001; Kepinski and Leyser 2004). One of the most rapidly auxin-inducible genes activated through this mechanism is the $\mathrm{GH} 3$ gene originally isolated from soybean (Hagen et al. 1984). The GH3 gene is specifically activated by the natural auxin IAA and all active auxin analogs tested; it does not respond to nutrients, other phytohormones, or structurally related compounds (Hagen and Guilfoyle 1985). Because the GH3 gene is auxin-inducible in nearly all plant tissues (Gee et al. 1991; Hagen et al. 1991), the $G H 3$ promoter provides an excellent tool for detection of auxin activity.

The role of auxin in determining root architecture has been elucidated in part through the use of auxin-resistant mutants such as the diageotropica ( $d g t)$ mutant of tomato. The $d g t$ mutant lacks lateral roots and demonstrates an inability to grow upward (Zobel 1972); it is auxin-resistant with regards to hypocotyl-elongation (Kelly and Bradford 1986), root growth (Muday et al. 1995), and auxin-inducible gene expression (Coenen et al. 2003; Mito and Bennett 1995; Nebenführ et al. 2000). The DGT gene encodes a cyclophilin protein whose exact role in auxin signaling is presently unclear $(\mathrm{Oh}$ et al. 2006). Absence of lateral roots in $d g t$ seedlings has been attributed to selective abolishment of auxin-induced cell division in developing lateral root primordia without inhibition of other cell divisions in the root necessary for lateral root initiation (Ivanchenko et al. 2006).

To better understand the effects of DAPG-producing P. fluorescens bacteria on root growth and development, we investigated the effects of DAPG on tomato seedling roots and potential interactions between DAPG and auxin signaling pathways. Here, we provide a more detailed description of the general phytotoxic effects of DAPG on plant root development. We demonstrate that DAPG alone, without the presence of added auxin, induces auxin-like effects on tomato seedling root development and that DAPG effects require a DGT-dependent auxin-signaling pathway.

\section{RESULTS}

\section{DAPG effects on tomato seedling development.}

At $50 \mu \mathrm{M}$, exogenous application of DAPG inhibited primary root growth and induced primary root tip necrosis as evidenced by browning (Fig. 1A). Hypocotyls and cotyledons demonstrated no visible necrosis; however, purple coloration of the hypocotyls indicated a stress response to $50 \mu \mathrm{M}$ DAPG. This concentration also inhibited opening of the hypocotyl hook (Fig. 1A) and induced exaggerated hook curvature upon longer exposure (Fig. 1B). At $10 \mu \mathrm{M}$, DAPG stimulated lateral root production in tomato seedlings without damaging the primary root (Fig. 1B). Lateral and adventitious roots produced at 50 $\mu \mathrm{M}$ DAPG did not show visible necrosis (Fig. 1B). Root hair development was not obviously affected by DAPG (absence of root hairs on some of the plants shown in Figure 1 is an artifact of poor resolution of hairs formed on roots growing into the agar surface). The effects of DAPG on primary root growth appeared to be irreversible, because transferring plants from DAPG onto fresh media failed to rescue primary root growth (data not shown).

Concentrations of $50 \mu \mathrm{M}$ DAPG or higher completely inhibited primary root growth at all timepoints of a 4-day exposure (Fig. 2A). Roots treated with 10 and $20 \mu \mathrm{M}$ DAPG showed growth inhibition during the initial $24 \mathrm{~h}$ of exposure but grew at rates similar to those of untreated roots during the remaining exposure time. The absence of inhibitory effects of low DAPG concentrations during later timepoints of prolonged exposure coincided with the slowing of growth in control seedlings (Fig. 2A). In the 4-day-old seedlings used for this experiment, lateral root formation was inhibited by as little as $1 \mu \mathrm{M}$ DAPG during the initial $72 \mathrm{~h}$ of treatment (Fig. 2B). However, the inhibitory effects of DAPG concentrations $<100 \mu \mathrm{M}$ were no longer detectable after an additional $24 \mathrm{~h}$ of treatment (Fig. 2B).

Although DAPG was found to be unstable in the light (Supplementary Fig. 1), its effects on primary root growth were similar for both light- and dark-incubated plants (Fig. 3A). In light-incubated plants, 5 to $20 \mu \mathrm{M}$ DAPG increased lateral root number in the 3.5-day-old seedlings used for this experiment (Fig. 3B). Because primary root growth was not inhibited at these lower concentrations, this stimulation could not be explained by a simple carbon reallocation effect from primary to lateral root growth. In contrast, lateral root number in darkincubated seedlings increased only at a concentration (i.e., 30 $\mu \mathrm{M})$ that inhibited primary root growth.

DAPG has been hypothesized to inhibit root proton secretion (Phillips et al. 2004), so it could inhibit primary root growth through this mechanism. To test directly whether DAPG inhibits proton secretion, we incubated tomato seedlings on bromocresol purple indicator agar for $2 \mathrm{~h}$. Under these conditions, application of $10 \mu \mathrm{M}$ DAPG to the roots failed to inhibit root proton secretion, whereas $50 \mu \mathrm{M}$ completely inhibited this process (Table 1).

\section{Interaction between IAA and DAPG in root growth regulation.}

The overlap of DAPG effects with typical auxin responses, such as the inhibition of primary root growth, stimulation of lateral root formation, and the inhibition of proton secretion by root tips, raises the possibility that the two substances use partially shared mechanisms of action. To test whether IAA and DAPG show antagonistic or synergistic effects on primary root growth, plants were simultaneously exposed to both IAA and DAPG (Fig. 4). Increasing concentrations of IAA neither increased nor rescued root growth inhibition by DAPG, suggesting that there was no obvious synergism or antagonism between these two compounds.

To test more directly whether DAPG inhibits primary root growth and stimulates lateral root production through an auxindependent signaling pathway, we compared DAPG effects on wild-type plants with those on the auxin-resistant $d g t$ mutant of tomato (Fig. 5). Primary roots of $d g t$ seedlings were slightly less sensitive to DAPG than wild-type primary roots, requiring approximately $50 \%$ higher DAPG concentrations for similar growth inhibitory effects (i.e., $>20 \mu \mathrm{M}$ DAPG). Low concentrations of DAPG also failed to stimulate lateral root formation in $d g t$. However, $d g t$ seedlings produced lateral roots in response to mechanical wounding of the root tip (data not shown) as well as 
in response to DAPG concentrations that caused primary root tip necrosis (Fig. 5). Therefore, high DAPG concentrations (i.e., $>20 \mu \mathrm{M}$ DAPG) may have stimulated lateral root production through pathways similar to wounding of the primary root tip, which are functional in $d g t$. Lack of stimulation of lateral root production by $\leq 20 \mu \mathrm{M}$ DAPG (Fig. 5B) indicated that this response may require a DGT-dependent auxin signaling pathway.

\section{Inhibition of luciferase activity by DAPG and} culture supernatants of DAPG-producing Pseudomonas spp.

To assess DAPG interactions with auxin signal transduction, we characterized the effects of pure DAPG on luciferase activity driven by the selectively auxin-responsive $G H 3$ promoter.
Despite its auxin-like effects on root development, application of DAPG alone failed to induce the auxin-responsive $G H 3$ promoter (data not shown). However, when applied prior to auxin treatment, DAPG fully inhibited auxin-induced $G H 3$ promoter activation at a concentration of $20 \mu \mathrm{M}$ (Fig. 6A), which is in the natural range of DAPG concentrations reported in the rhizosphere (Bonsall et al. 1997).

Similar to synthetic DAPG, supernatants from phlD+ $P$. fluorescens cultures completely inhibited luciferase activity in GH3::Luc tobacco hypocotyl segments treated with $10 \mu \mathrm{M}$ IAA (Fig. 6B). This pattern of suppression occurred with representative strains of three different phlD restriction fragment length polymorphism-defined genotypes (i.e., A, S, and D; data

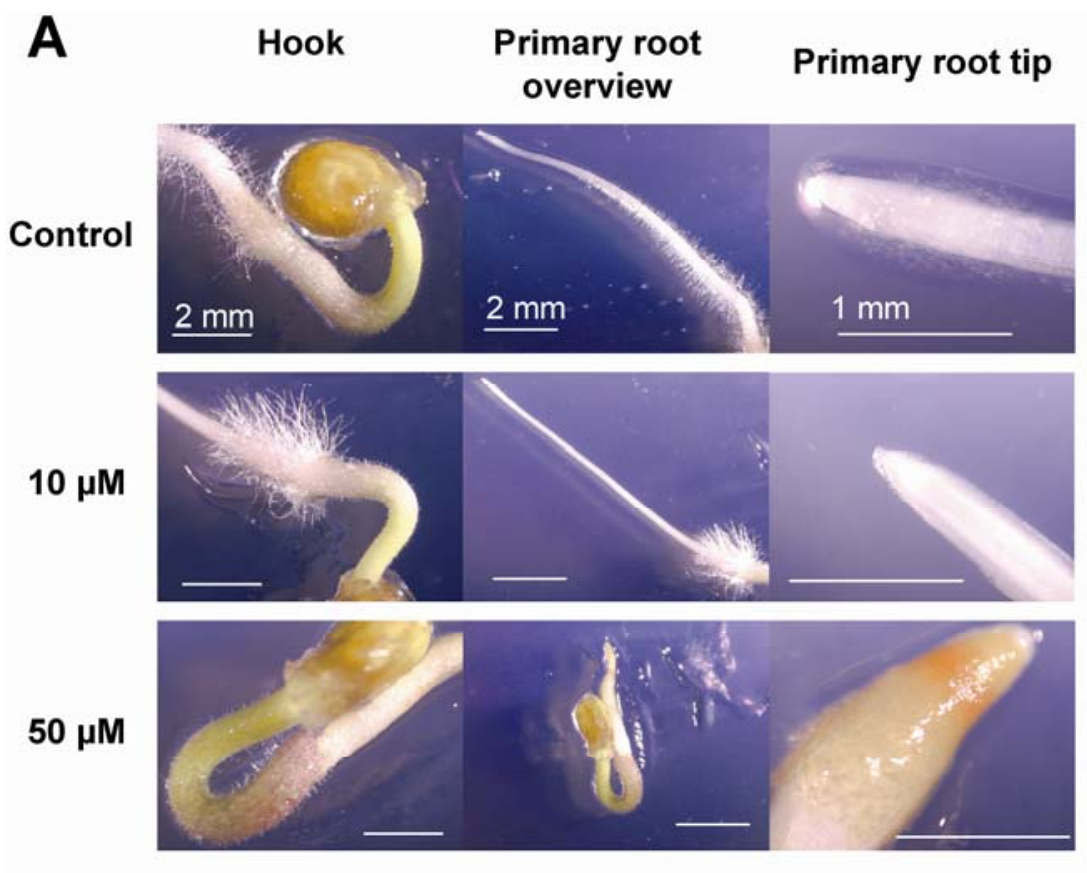

B
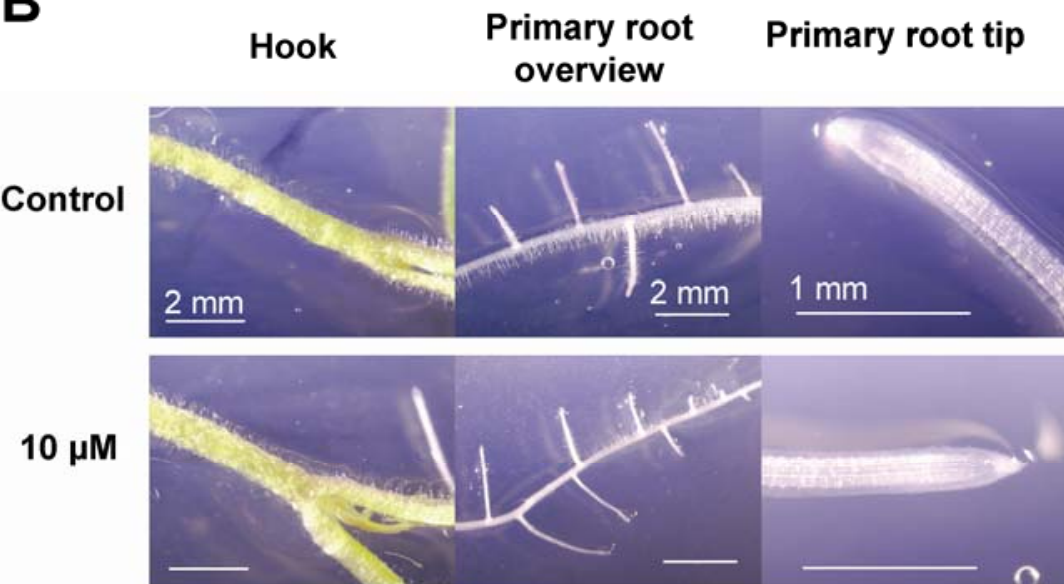

\section{Adventitious root tip}

$50 \mu \mathrm{M}$

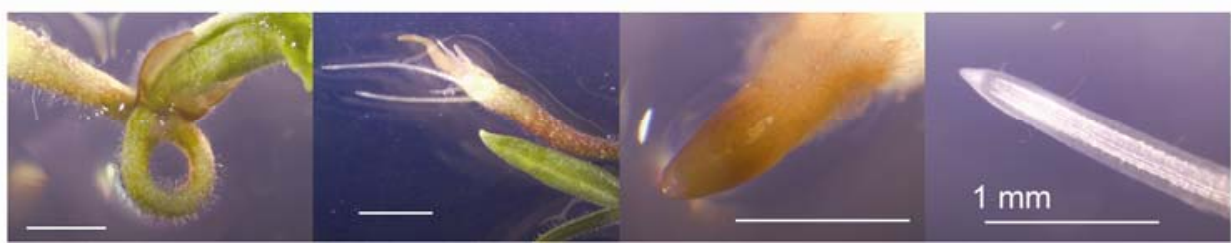

Fig. 1. 2,4-Diacetylphloroglucinol (DAPG) effects on root development in tomato seedlings. Representative examples of tomato seedlings incubated in the light for A, 1 and B, 4 days on plates containing the indicated concentrations of DAPG. Seedlings were photographed using a digital camera with Spot RT software attached to a dissecting microscope. Seedling organs were photographed at magnifications of $\times 1.5$ (hypocotyl hook), $\times 0.75$ (primary root overviews), or $\times 6$ (root tips). Note that root hairs on some of the roots shown here are not visible due to growth of the root into the agar surface, so that root hair development cannot be interpreted based on this illustration. 
not shown). The inhibition of luciferase activity was already apparent at the first timepoint of the preincubation period (Fig. 6B), approximately 19 min after supernatant addition. Inhibition kinetics of auxin-induced gene expression also were assessed by adding DAPG or supernatants from $P$. fluorescens strain Wayne $1 \mathrm{R}$ after the auxin response was already initiated (Fig. 7). The time course of the culture supernatant-induced inhibition was similar to the inhibition caused by addition of $30 \mu \mathrm{M}$ DAPG.

A

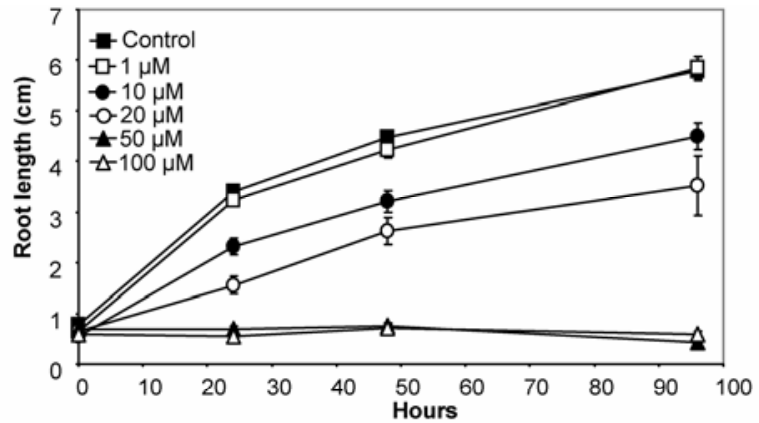

B

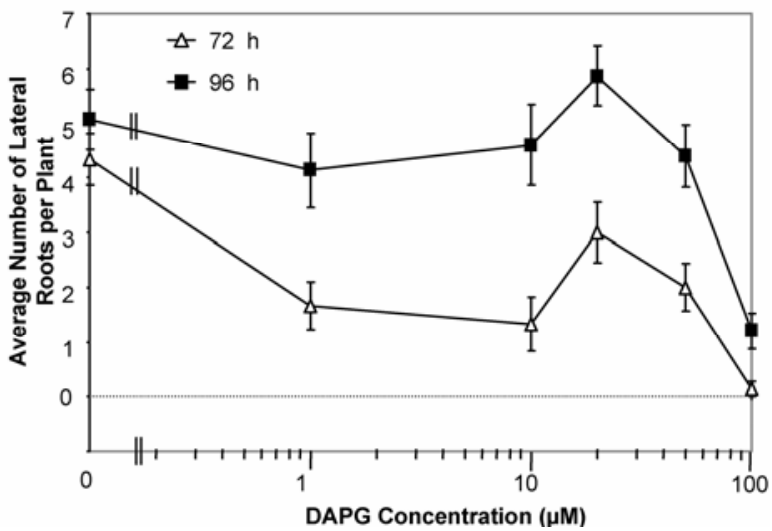

Fig. 2. Time effects on 2,4-diacetylphloroglucinol (DAPG) inhibition of tomato seedling root growth. A, Primary root growth and $\mathbf{B}$, lateral root number per plant. Four days after sowing, tomato seedlings with roots 5 to $10 \mathrm{~mm}$ in length were moved to plates containing the indicated concentrations of DAPG and incubated for 4 days in the light. Three plates containing five seedlings each were used for each treatment, and each plate was scanned once every $24 \mathrm{~h}$ to determine root lengths using APS Assess software. Data points represent the average primary root length at each measuring timepoint. Lateral roots were counted by viewing plants at $\times 8 \mathrm{mag}$ nification through a Nikon dissecting microscope at 72 and $96 \mathrm{~h}$ after start of exposure to DAPG. Error bars represent standard error of the mean $(n=$ 15). This experiment was repeated three times with similar results, and one representative experiment is shown here.

Table 1. Proton secretion by tomato roots exposed to 2,4-diacetylphloroglucinol (DAPG) ${ }^{\mathrm{a}}$

\begin{tabular}{lcc}
\hline $\begin{array}{l}\text { DAPG } \\
(\boldsymbol{\mu M})\end{array}$ & $\begin{array}{c}\text { No. of seedlings secreting protons/ } \\
\text { no. of seedlings scored }\end{array}$ & $\begin{array}{c}\text { Color of } \\
\text { root tip }\end{array}$ \\
\hline 0 & $4 / 4$ & White \\
1 & $4 / 4$ & White \\
10 & $4 / 4$ & White \\
20 & $3 / 5$ & White \\
30 & $2 / 5$ & White \\
50 & $0 / 5$ & Brown \\
100 & $0 / 5$ & Brown \\
\hline
\end{tabular}

${ }^{\mathrm{a}}$ Tomato seedlings were pregerminated for 4 days until root tips were 2 to $10 \mathrm{~mm}$ in length, moved to half-strength Murashige and Skoog salt plus $0.8 \%$ tissue culture grade agar plates containing bromocresol purple and the indicated concentrations of DAPG, and incubated at room temperature for $4 \mathrm{~h}$. Seedlings were scored for proton secretion based on yellow coloration of indicator dye immediately surrounding root tips and root hair zone.
Because $P$. fluorescens is known to produce a wide range of secondary metabolites in addition to DAPG, we compared the effects of supernatants from the fully sequenced strain Pf-5 with those of a $p h l D^{-}$mutant of this strain. Supernatants from both Pf-5 and mutant cultures rapidly inhibited luciferase activity (Fig. 8), indicating that DAPG is not the sole inhibitor in these supernatants. However, two independent experiments confirmed that Pf-5 supernatant effects were significantly more rapid than those of supernatants from mutant cultures: One hour after replacement of the incubation media with culture supernatants, the average inhibition relative to the last preaddition timepoint was significantly greater for Pf-5 supernatants than for $p h l D^{-}$supernatants. (experiment I: Pf-5 average inhibition $=78.9 \pm 2.3 \%, n=16, p^{-} D^{-}$average inhibition $=65 \pm$ $2.8 \%, \mathrm{n}=15$; experiment II: Pf-5 average inhibition $=95.6 \pm$ $0.7 \%, n=24, p h l D^{-}$average inhibition $\left.=77.7 \pm 1.6 \%, n=24\right)$. These results were found to be highly significant, with $P<$ 0.002 for experiment I and $P<0.0001$ for experiment II. Because thin-layer chromatography (TLC) analysis of supernatants from mutant cultures confirmed loss of DAPG synthesis in the mutant (not shown), these experiments indicate that at least one other $P$. fluorescens metabolite has inhibitory activity in this system.

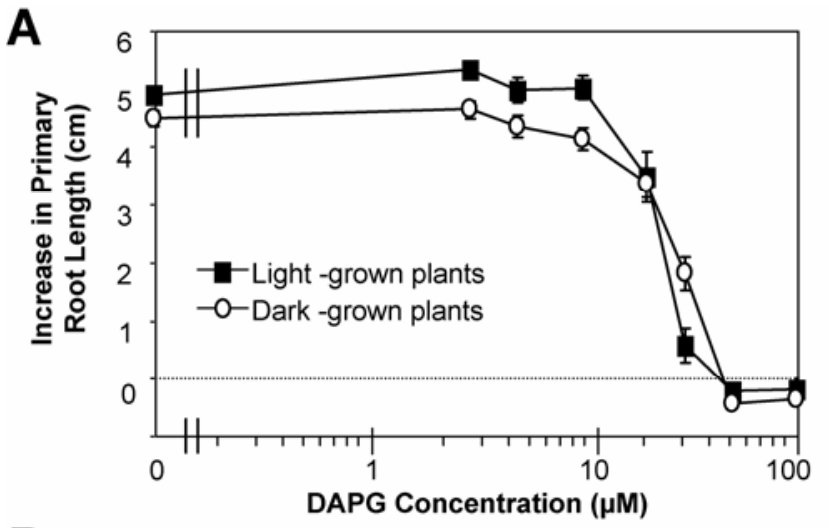

B

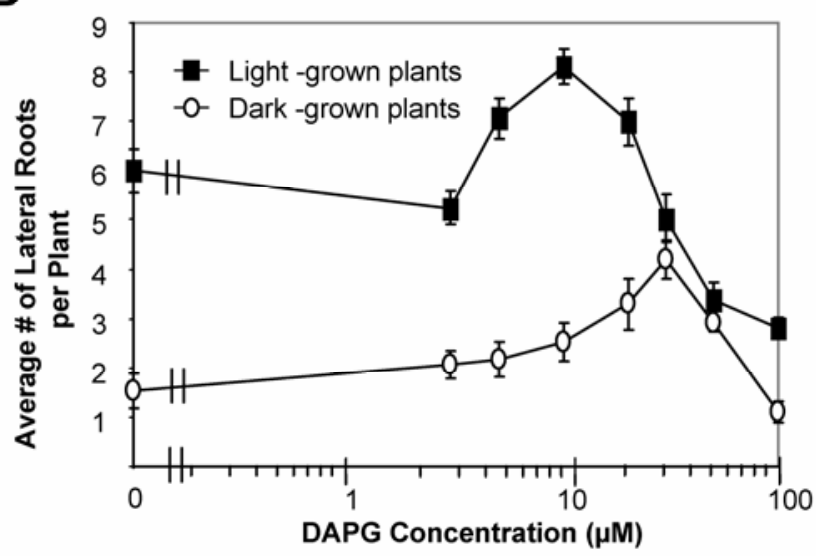

Fig. 3. Light modulation of 2,4-diacetylphloroglucinol (DAPG) effects on primary root growth and lateral root number in tomato plants after $96 \mathrm{~h}$ of exposure. Seedlings with roots approximately 2 to $6 \mathrm{~mm}$ in length $(3.5$ days after sowing) were moved to plates containing the indicated concentrations of DAPG and incubated in either light $(16 \mathrm{~h}$ of light and $8 \mathrm{~h}$ of darkness) or continuous darkness for $96 \mathrm{~h}$. Squares and circles represent light- and dark-grown plants, respectively. Root lengths were measured by ruler immediately after transfer to treatment plates and after $96 \mathrm{~h}$; the increase in length of each root during the time of DAPG exposure was calculated and averaged. Six plates containing five seedlings each were used for each DAPG treatment, and error bars represent the standard error of the mean $(n=30)$. This experiment was repeated three times with similar results; one representative experiment is shown here. 


\section{DISCUSSION}

At concentrations reported to exist in situ (Bonsall et al. 1997) and that can induce plant host defenses (Iavicoli et al. 2003), we observed that DAPG caused drastic changes in root physiology and morphology. These changes included the development of brown and shriveled root tips and swollen root zones, inhibition of primary root growth, and stimulation of root branching (Figs. 1 through 3). Such changes in root tissues may also indirectly stimulate host defense pathways. Although multiple pseudomonad factors may induce such responses in plant hosts (Bakker et al. 2007; Meziane et al. 2005), both DAPG-producing pseudomonads and 10 to $100 \mu \mathrm{M}$ DAPG applied exogenously to Arabidopsis thaliana have been reported to induce resistance to foliar infections by Peronospora parasitica (Iavicoli et al. 2003). An interaction between DAPG and auxin signaling may partly explain the resistance-inducing properties of this compound, because modification of auxin balance in host plant tissues is associated with the development of disease symptoms (Chen et al. 2007).

Although it is unclear if all crop plants respond to DAPG by altering their root architecture, similar DAPG sensitivities for a wide range of crop species (Keel et al. 1992) may indicate that DAPG's effects on plant roots may be universal. Here, DAPG concentrations causing half-maximal inhibition of primary root growth in tomato (20 to $30 \mu \mathrm{M} \mathrm{DAPG)} \mathrm{(Fig.} \mathrm{3)} \mathrm{were}$ close to the minimal DAPG concentrations reported to inhibit overall tomato growth by $50 \%(76 \mu \mathrm{M})$ (Keel et al. 1992), suggesting that growth inhibition in the primary root is only partially offset by increased lateral root production over the lengthier incubation periods reported in the earlier experiments.

Restriction of DAPG-induced necrosis to specific zones of the primary root indicates that DAPG sensitivity or response mechanisms differ between specific cell types or developmental stages of the root. The distinct local confinement of necrosis to meristematic regions of primary root tips (Fig. 1) indicates that DAPG toxicity may primarily occur in rapidly dividing cells. This localized sensitivity was further supported by the fact that the more systemic responses of shoots and elsewhere on the root were consistent with non-necrotic stress responses. Although DAPG producers may represent approximately 1 to $10 \%$

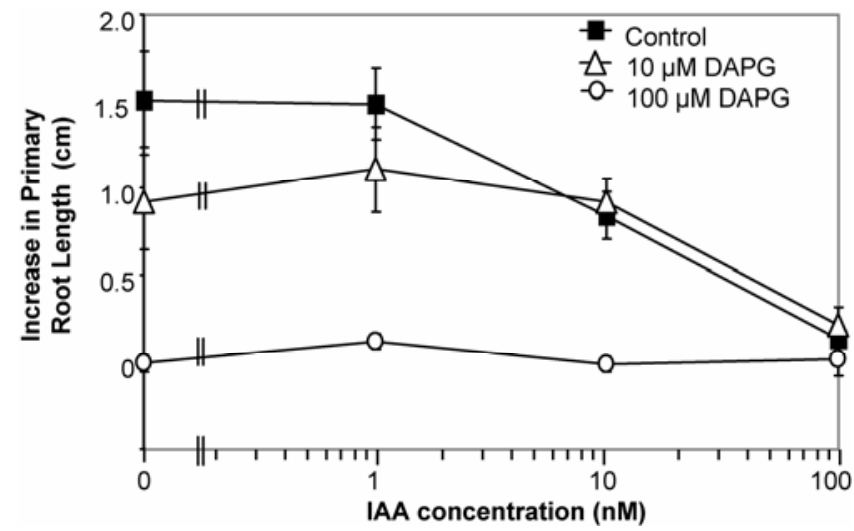

Fig. 4. Primary root growth in tomato seedlings exposed to 2,4-diacetylphloroglucinol (DAPG) and indole-3-acetic acid (IAA). Seedlings with roots approximately 2 to $6 \mathrm{~mm}$ in length (3.5 days after sowing) were moved to plates containing the indicated concentrations of DAPG and IAA. Root length was measured with the help of APS Assess software immediately after transfer to treatment plates and after $24 \mathrm{~h}$ of incubation at $26^{\circ} \mathrm{C}$ under a light and dark cycle of 16 and $8 \mathrm{~h}$, respectively. Error bars represent standard error of the mean for the increase in root length exhibited by fifteen seedlings grown on three separate plates. The experiment was repeated three times with similar results; one representative experiment is shown here. of the root-colonizing pseudomonads (McSpadden Gardener et al. 2005), they have been estimated to colonize no more than $0.1 \%$ of the root surface, and DAPG concentrations may vary widely as a result (Haas and Keel 2003). Therefore, local DAPG concentrations produced by phlD+ pseudomonads likely vary dramatically across the root, and bacterially produced DAPG concentrations in natural systems may rarely reach toxic levels in the most sensitive root zones (i.e., primary root tip). Although the typical distribution of DAPG producers on field grown roots remains unclear, Aino and associates (1997) demonstrated that two strains could move toward tomato root tips with growth of the root and form colonies as well as DAPG crystals inside and around the roots. This indicates that at least some phlD+ Pseudomonas strains may be able to produce sufficiently high DAPG concentrations near the root tip to inhibit growth and, subsequently, stimulate secondary root growth. Whether such a response would generally benefit plant health or vigor remains unclear. However, the abundance of DAPG producers often has been positively correlated with stands and yields of corn (Rotenberg et al. 2007), a crop species that relies heavily on a frequently branching root system to access nutrients and is known to harbor relatively high populations of DAPG-producing pseudomonads (McSpadden Gardener et al. 2005). It would be interesting to see whether the abundance
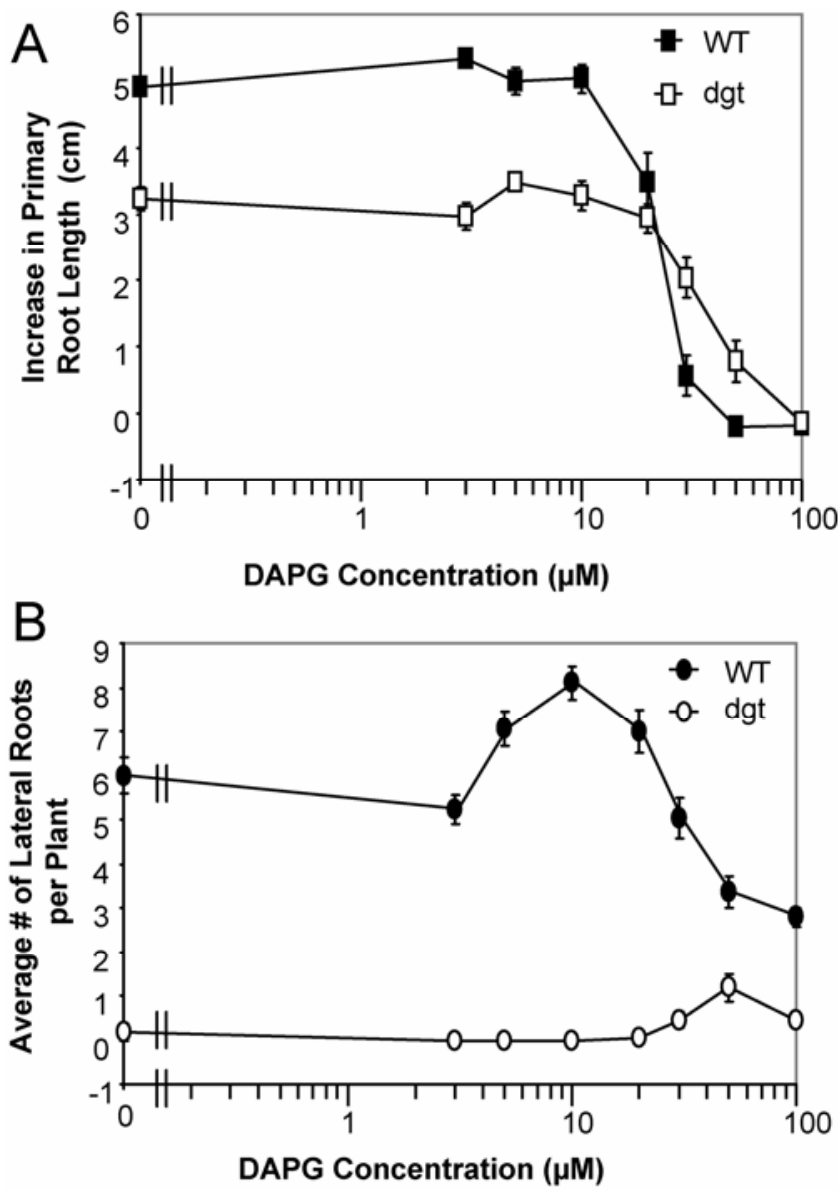

Fig. 5. 2,4-Diacetylphloroglucinol (DAPG) effects on root growth and lateral root initiation in diageotropica (dgt) tomato seedlings. A, Primary root growth and $\mathbf{B}$, lateral root number; WT $=$ wild type. Tomato seedlings with roots approximately 2 to $6 \mathrm{~mm}$ in length were moved to plates containing the indicated concentrations of DAPG. After $96 \mathrm{~h}$ at $26^{\circ} \mathrm{C}$ and a light and dark cycle of 16 and $8 \mathrm{~h}$, respectively, the number of lateral roots was counted and primary root lengths were measured by ruler. Six plates containing five seedlings each were used for each DAPG treatment, and error bars represent the standard error of the mean. This experiment was repeated three times with similar results; one representative experiment is shown here. 
of DAPG producers, the amount of root branching, and crop vigor are also correlated in field-grown tomato and other dicot crops.

DAPG concentrations too low to inhibit pathogen growth directly are known to change gene expression in both bacteria and plants (Haas and Keel 2003) and, thus, may profoundly influence development. In tomato, DAPG-induced changes in root physiology were complex and dependent on developmental stages of roots, suggesting that DAPG may act through multiple mechanisms. The increased initiation and growth of lateral roots in response to DAPG (Figs. 1 and 3) indicated that DAPG does not act exclusively by inducing cell death. Consistent with increased sensitivity of rapidly growing or dividing cells to DAPG action, the effects of DAPG on both primary root growth and lateral root number were less evident as incubation time on DAPG increased and growth of control roots slowed (Fig. 2A and B). In addition, stimulation of lateral root production in the slightly older plants used in this experiment was less pronounced than in experiments using younger seedlings (compare Figs. 2B and 3B), indicating that root sensitivity to DAPG may be under developmental control. After $96 \mathrm{~h}$
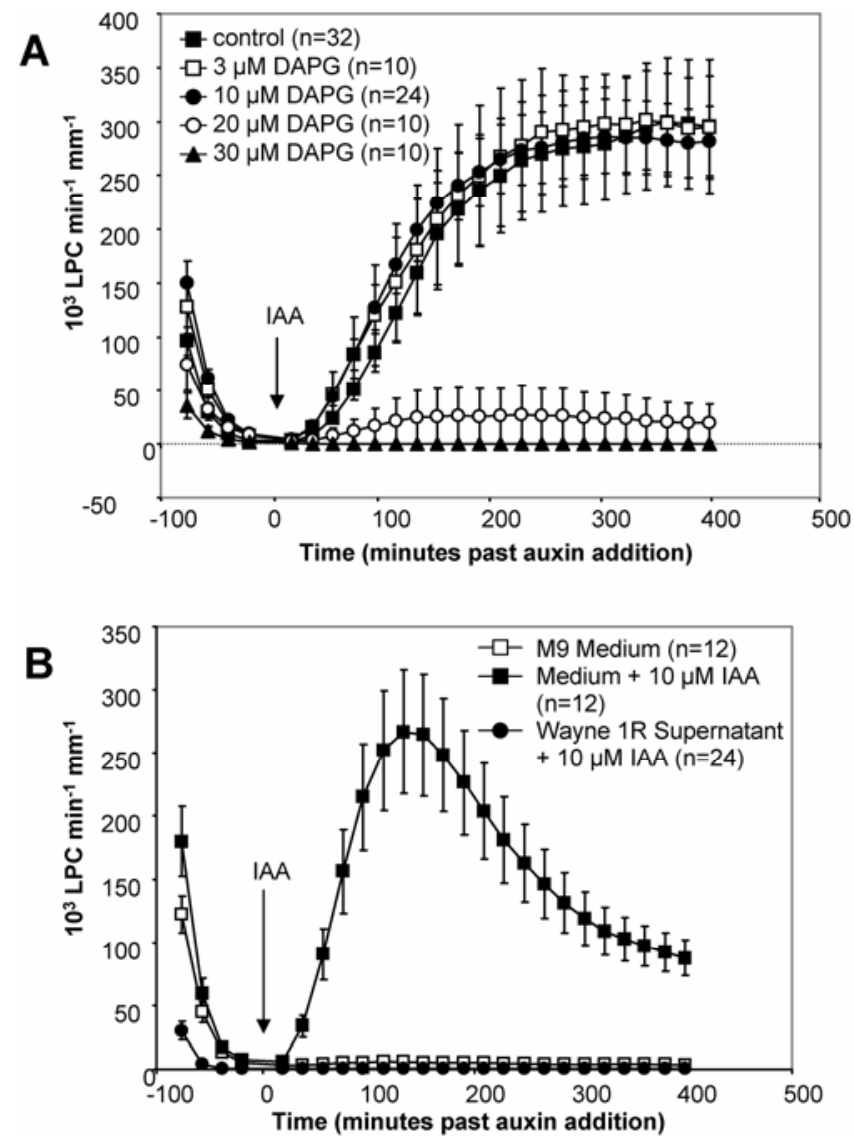

Fig. 6. Effects of 2,4-diacetylphloroglucinol (DAPG) and supernatants from Pseudomonas fluorescens cultures on luciferase activity in tobacco hypocotyls carrying the GH3::Luc construct. A, Concentration dependence of DAPG effects on luciferase activity. Excised GH3::Luc hypocotyls were incubated in a phosphate buffer containing $1 \mathrm{mM}$ luciferin, $10 \mathrm{mM}$ potassium phosphate, and the indicated concentrations of DAPG. Indole3 -acetic acid (IAA) was added to a final concentration of $10 \mu \mathrm{M}$ after 80 min (time 0). Data shown were compiled from two separate experiments, and sample size $(n)$ for each treatment is listed in the legend. B, P. fluorescens supernatant effects on luciferase activity. Excised GH3::Luc tobacco hypocotyls were preincubated in $75 \% \mathrm{M} 9$ media containing $1 \mathrm{mM}$ luciferin. IAA was added to a final concentration of $10 \mu \mathrm{M}$ after 80 min (time 0 ). Luminescence counts were repeated every $19 \mathrm{~min}$. Error bars represent the standard error of the mean. This experiment was repeated six times with similar results. $\mathrm{LPC}=$ luminescent photon counts. of exposure, lateral root meristems may have adapted to the presence of DAPG (Fig. 2B), an interpretation that is supported by absence of necrosis in lateral root tips. Alternatively, DAPG concentrations in the media may have fallen below inhibitory levels prior to initiation or emergence of the lateral roots. Loss of primary root growth inhibitory effects of DAPGcontaining media after 4 days of incubation in the light and the loss of lateral root inhibition between 72 and $96 \mathrm{~h}$ post DAPG application (Fig. 2B) support this latter interpretation.

Several lines of evidence indicate that DAPG effects on plant tissues are rapid. Auxin-induced luciferase activity of tobacco hypocotyl segments decayed within minutes of DAPG application (Fig. 7), root tip browning (Fig. 1) became evident within hours of DAPG application, and inhibition of proton secretion by root tips (Table 1) and root growth (Fig. 2) were evident at the earliest timepoint at which these responses were assessed (4 and $24 \mathrm{~h}$, respectively). This rapid action of DAPG likely explains why this compound affected root growth in
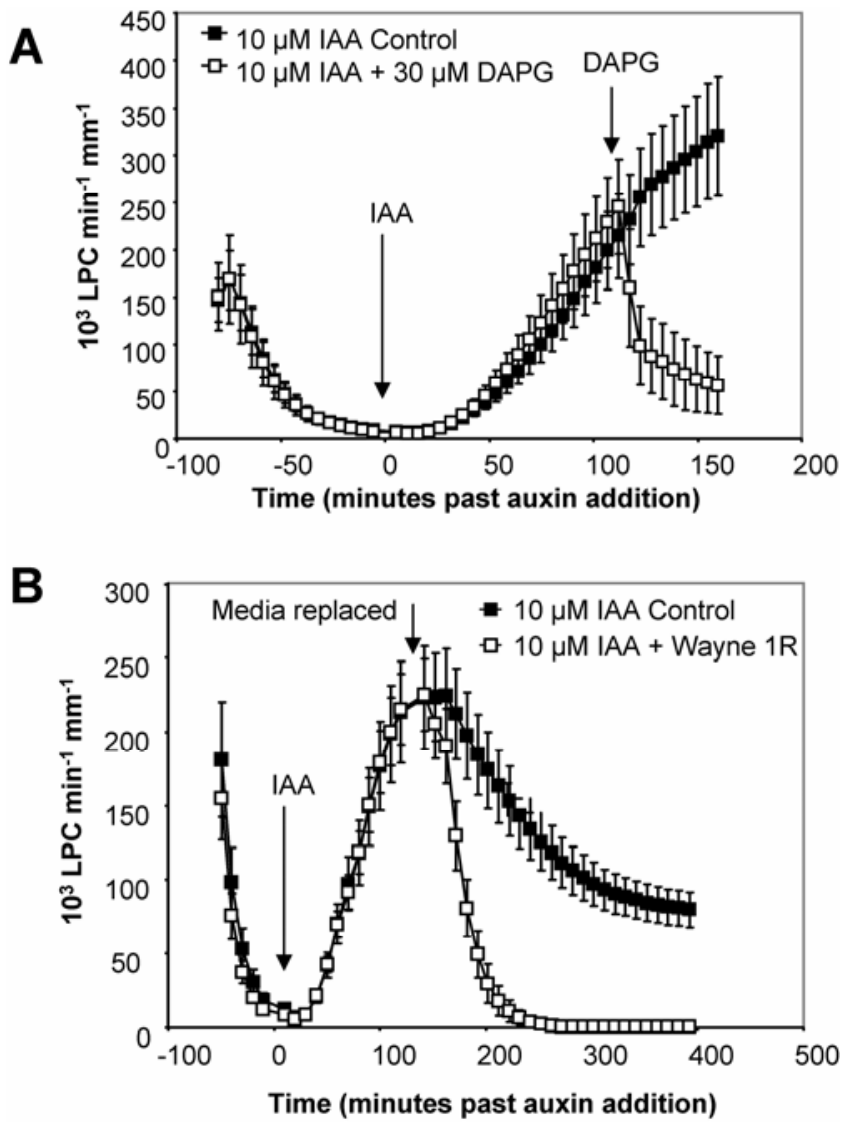

Fig. 7. Inhibition kinetics of luciferase activity by 2,4-diacetylphloroglucinol (DAPG) and Pseudomonas fluorescens supernatants. A, Time course of DAPG action. Excised GH3::Luc hypocotyls were incubated in buffer containing $1 \mathrm{mM}$ luciferin and $10 \mathrm{mM}$ potassium phosphate. Indole-3-acetic acid (IAA) was added to a final concentration of $10 \mu \mathrm{M}$ after $80 \mathrm{~min}$ (time 0), and DAPG was added to a final concentration of $30 \mu \mathrm{M} 120 \mathrm{~min}$ after indole-3-acetic acid (IAA) addition. Luminescence counts were repeated every $4 \mathrm{~min}$. This experiment was repeated twice with similar results, $n=12$ for both treatments as shown in this representative experiment. B, Time course of $P$. fluorescens effects. Excised GH3::Luc hypocotyls were incubated in $75 \%$ M9 medium containing $1 \mathrm{mM}$ luciferin. IAA was added to a final concentration of $10 \mu \mathrm{M}$ after $80 \mathrm{~min}$ (time 0 ), and media were replaced $120 \mathrm{~min}$ later with either $1 \mathrm{mM}$ luciferin and $10 \mu \mathrm{M}$ IAA in $75 \%$ M9 medium or $1 \mathrm{mM}$ luciferin and $10 \mu \mathrm{M}$ IAA in $75 \%$ supernatant from P. fluorescens strain Wayne 1R. Luminescence counts were repeated every $10 \mathrm{~min}$. Error bars represent the standard error of the mean. The experiment was repeated twice with similar results; for the representative experiment shown here, $n=11$ and 10 for the control and supernatant treatments, respectively. $\mathrm{LPC}=$ luminescent photon counts. 
light- and dark-incubated seedlings similarly (Fig. 3), despite its ability in the light. Loss of DAPG effects in light-incubated medium also explains release of roots from the inhibition of growth (Fig. 2A) and lateral root formation (Fig. 2B) during prolonged incubation.

Induction of lateral root primordia is usually associated with the accumulation of auxin in pericycle cells. If DAPG stimulates lateral root initiation via an auxin-dependent signaling pathway, this response should be absent in the auxin-resistant tomato mutant $d g t$, which does not show auxin-induced lateral root formation (Ivanchenko et al. 2006). Primary root growth of $d g t$ seedlings was less sensitive to DAPG than wild-type root growth, requiring 50\% higher concentrations for a similar effect (Fig. 5), suggesting a link between auxin signaling and DAPG sensitivity. Low concentrations of DAPG failed to stimulate lateral root development in $d g t$, indicating that the cyclophilin protein encoded by the DGT gene product (Oh et al. 2006) is required for this DAPG response. Because $d g t$ roots initiate new lateral roots in response to mechanical wounding of the primary root tip (data not shown), stimulation of root branching by DAPG concentrations that kill the primary root tip could be mediated by pathways similar to those elicited by a wound response. Although simultaneous application of DAPG and IAA to growing tomato seedlings demonstrated no obvious synergism or antagonism between the effects of these two compounds on tomato primary root growth (Fig. 4), the DGT dependence of DAPG effects on root development suggest an interaction between DAPG and auxin signaling.

Auxin is known to block proton secretion at the tomato root tip (Coenen et al. 2002), and DAPG has been speculated to block root proton secretion as one possible mechanism underlying its effects on amino acid secretion (Phillips et al. 2004). Although root proton secretion on plates containing the $\mathrm{pH}$ indicator dye bromocresol purple was indeed blocked by DAPG (Table 1), the concentrations required for this response also elicited necrosis, making it impossible to determine whether the inhibition of proton secretion was the cause or

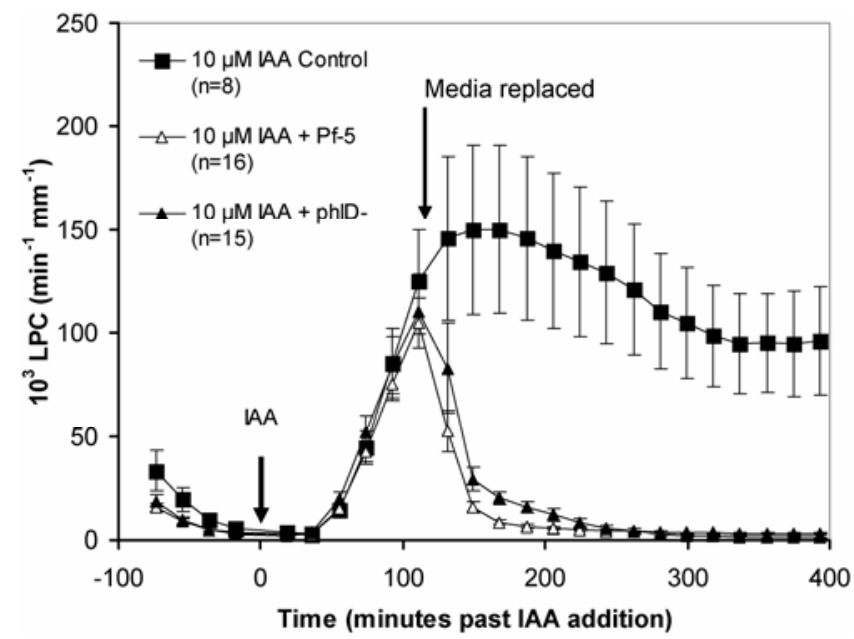

Fig. 8. Inhibition kinetics of luciferase activity by supernatants from 2,4-diacetylphloroglucinol (DAPG)-producing Pseudomonas fluorescens cultures and from a $p h l D^{-}$mutant. Excised $G H 3:: L u c$ hypocotyls were incubated in $75 \%$ M9 medium containing $1 \mathrm{mM}$ luciferin. Indole-3-acetic acid (IAA) was added to a final concentration of $10 \mu \mathrm{M}$ after $80 \mathrm{~min}$ (time 0 ), and media were replaced $120 \mathrm{~min}$ later with $1 \mathrm{mM}$ luciferin and $10 \mu \mathrm{M}$ IAA in $75 \% \mathrm{M} 9$ medium, $1 \mathrm{mM}$ luciferin and $10 \mu \mathrm{M}$ IAA in $75 \%$ supernatant from $P$. fluorescens strain Pf-5, or $1 \mathrm{mM}$ luciferin and $10 \mu \mathrm{M}$ IAA in $75 \%$ supernatant from the phlD ${ }^{-}$mutant of $P$. fluorescens strain Pf-5. Luminescence counts were repeated every $19 \mathrm{~min}$. Error bars represent the standard error of the mean. The experiment was repeated twice with similar results; one representative experiment is shown. $\mathrm{LPC}=$ luminescent photon counts. consequence of root cell death. Because auxin inhibition of proton secretion is not accompanied by necrosis of the root tip, it seems unlikely that DAPG and IAA use similar mechanisms to effect this response.

Although early studies suggested that DAPG effects may be 2,4-D-like (Reddi et al. 1969), DAPG failed to stimulate the activity of the $G H 3$ promoter (not shown), which is 2,4-D responsive (Hagen et al. 1991). Although DAPG's failure to activate the $G H 3$ promoter suggests that it does not act via the same signal transduction pathways as other auxins, it could elicit auxin-like effects on root development by altering cellular auxin sensitivity or auxin transport, either directly, as recently shown for volatiles emitted by a plant growth promoting strain of Bacillus subtilis (Zhang et al., 2007), or through stimulation of ethylene synthesis. Hook curling exhibited by tomato seedlings in response to $50 \mu \mathrm{M}$ DAPG (Fig. 1B) is part of the classic ethylene triple response, and ethylene is a known regulator of root auxin synthesis (Stepanova et al. 2005) and transport (Lee et al. 1990). Ethylene effects on patterns of auxin transport may be due to ethylene-induced flavonoid synthesis (Buer et al. 2006). However, DAPG-induced increases in root branching occurred at a lower DAPG concentration than DAPG-induced hook curling and anthocyanin synthesis (Fig. 1), suggesting that mediation of DAPG effects through ethylene could be limited to high DAPG concentrations.

Although DAPG's antibiotic effects on plant pathogens are well documented (de Souza et al. 2003; Schouten et al. 2004) and consistent with the biocontrol activity of phlD+Pseudomonas isolates (Keel et al. 1992), the complete spectrum of effects conferred by DAPG producers has yet to be fully characterized. Our finding that DAPG may interact with auxin signaling to modify root architecture suggests that DAPG may exert direct growth regulatory effects in addition to its antibiotic activity toward plant pathogens. The pleiotropic, complex, and developmentally dependent effects of DAPG on tomato roots suggest that its action mechanisms may involve multiple molecular targets. We expect that the mechanisms underlying DAPG's activities related to both plant protection and plant development are varied and context dependent. Comprehensive genomic analyses, such as those now being undertaken with strain Pf-5 (Loper et al. 2007) and other biocontrol pseudomonads, will likely lead to a much more comprehensive description of the varied metabolic activities that contribute to biocontrol and plant growth promotion by DAPG-producing strains.

\section{MATERIALS AND METHODS}

\section{Plant materials and culture.}

Seed of the dgt mutant of tomato (Lycopersicon esculentum) and its parent cultivar, Ailsa Craig, were originally obtained from Charles Rick at the University of California, Davis. Seed used in this study were from plants grown in the Allegheny College greenhouse. Seed were surface sterilized in $20 \%$ household bleach for $20 \mathrm{~min}$, rinsed with at least $700 \mathrm{ml}$ of sterile distilled water, and plated on half-strength Murashige and Skoog salt (Murashige and Skoog 1962) and 0.8\% tissue culture grade agar (both from PhytoTechnology Labs, Lenexa, KS, U.S.A.) (MSO) medium. Seed were incubated at $26^{\circ} \mathrm{C}$ with a light and dark cycle of 16 and $8 \mathrm{~h}$, respectively, for 72 to $96 \mathrm{~h}$, until root tips were 2 to $10 \mathrm{~mm}$ in length.

Tobacco (Nicotiana plumbaginifolia) plants transformed with gene constructs containing the auxin-inducible $G H 3$ promoter (Hagen et al. 1991) linked to a luciferase reporter gene were generated by ligating promoter-luciferase cassettes into binary vectors derived from pBin19 (Bevan 1984), which were already carrying selectable kanamycin markers in their T-DNA region and had been modified by insertion of a pUC18 poly- 
linker site. Following Agrobacterium-mediated transformation of the T-DNA into leaf disk cells (Fillatti et al. 1987), several independent, kanamycin-resistant shoots from the explants were regenerated into plants. $\mathrm{A} \mathrm{T}_{2}$ line (64E) of seeds homozygous for the transgene construct was used in all experiments. Seeds were surface sterilized with $35 \%$ household bleach for 25 min while shaking continuously, rinsed five times with sterile double-distilled water, and incubated overnight in $1 \mathrm{mM}$ gibberellic acid at $4^{\circ} \mathrm{C}$. After several rinses to remove adhering gibberellic acid solution, seeds were plated on MSO medium and placed in a light incubator at $26^{\circ} \mathrm{C}$, with a light and dark cycle of 16 and $8 \mathrm{~h}$, respectively, until the root tip barely protruded from the seed coat (approximately $72 \mathrm{~h}$ ). Seedlings were then incubated in darkness at $26^{\circ} \mathrm{C}$ for an additional $48 \mathrm{~h}$ to permit hypocotyls to elongate.

\section{Bacterial culture.}

Strains of DAPG-producing Pseudomonas fluorescens (Cosh1R, Clinto1R, Crawf1R, Delaw1R, Darke1R, Henry1R, Huron1R, Preble1R, Wayne1R, Wood3R, Wyand2R, Wood1R, Clarke1R, Wayne1RB, Wood1RB, and Eaton 2) isolated from fields in Ohio (McSpadden Gardener et al. 2005), as well as the $p h l D^{-}$mutant and its isogenic parent strain, Pf-5 (Loper et al. 2007), were cultured initially on half-strength tryptic soy agar plates (EMD Chemicals, Gibbstown, NJ, U.S.A.) at $27^{\circ} \mathrm{C}$, and single colonies were used to inoculate half-strength tryptic soy broth (tryptic soy extract at $15 \mathrm{~g} \mathrm{liter}^{-1}$ ). For experiments assessing effects of supernatants from the Ohio strains on luciferase activity in tobacco hypocotyl segments, $25 \mu \mathrm{l}$ of 24 h-old broth cultures were used to inoculate $3 \mathrm{ml}$ of M9 broth supplemented with $500 \mu \mathrm{M}$ tryptophan. For experiments on Pf-5 and the phlD ${ }^{-}$mutant, $4 \mathrm{ml}$ of half-strength tryptic soy broth were inoculated with single colonies. All broth cultures were grown in the dark at $26^{\circ} \mathrm{C}$ while shaking at $200 \mathrm{rpm}$.

\section{Construction of the $\mathrm{phlD}^{-}$mutant of Pf-5.}

The construct used to generate the $p h l D^{-}$mutant was created using an overlap extension polymerase chain reaction (PCR) method modified from Choi and Schweizer (2005). All PCR was performed using KOD Hot Start DNA polymerase (Novagen, Madison, WI, U.S.A.). In the first round of PCR, 5' and 3' phlD gene fragments were amplified using the following primers: phlD UpF-Hind, 5'-GACGAAGACGAAGCTTCCTA CAGATTCCTGTGCCTA-3'; phID UpR-FRT, 5'-TCAGAGC GCTTTTGAAGCTAATTCGACACGATCAGTACGTGGTT G-3'; phlD DnF-FRT, 5'-AGGAACTTCAAGATCCCCAATT CGAGAGCGAGCACTACATCAAG-3'; and phlD DnR-Hind, 5'-GTGGTTGTGGAAGCTTTGGTTGGCATTCCAGTGTT C-3'. Amplification of the gentamycin resistance gene cassette from pPS856 (Hoang et al. 1989) was performed with the Gm$\mathrm{F}$ and Gm-R primers essentially as described (Choi and Schweizer 2005). In the second-round PCR, $50 \mathrm{ng}$ each of the phlD Up, phlD Dn, and FRT-gentamycin-FRT cassette PCR products were used to perform three rounds of amplification without added primers. The phlD UpF-Hind and phlD DnRHind primers were added halfway through the third cycle extension. Amplification of the full-length product was completed with an additional 25 cycles of PCR. The second-round PCR product was digested with HindIII and cloned into the HindIII site of pEX18Tc (Hoang et al. 1989). This construct was transformed into One Shot TOP10 Chemically Competent Escherichia coli cells (Invitrogen, Carlsbad, CA, U.S.A.) and confirmed by sequencing.

The deletion construct was transformed into the mobilizing strain E. coli S17-1 (Simon et al., 1983) and introduced into Pf-5 via conjugation. Pf-5 transconjugants were selected on King's medium B (KMB) (King et al. 1954) with streptomycin
$(100 \mu \mathrm{g} / \mathrm{ml}$, innate resistance of Pf-5) and gentamycin $(40 \mu \mathrm{g} /$ $\mathrm{ml})$. Colonies were grown for $3 \mathrm{~h}$ without selection in LuriaBertani (LB) broth and then plated on LB medium with gentamycin $(40 \mu \mathrm{g} / \mathrm{ml})$ and $5 \%$ sucrose to favor growth of resolved merodiploids. Sucrose-resistant colonies were patched onto KMB containing tetracycline $(200 \mu \mathrm{g} / \mathrm{ml})$ to confirm resolution of merodiploids. Tetracycline-sensitive, gentamycin-resistant clones were considered to be putative mutants. To remove the gentamycin resistance gene, the plasmid pFLP2 Km expressing Flp recombinase was introduced into the Pf-5 mutant by conjugation. pFLP2Km was constructed through introduction of the kanamycin resistance cassette from pUC4K (Vieira and Messing 1982) into the unique ScaI site of pFLP2 (Hoang et al. 1989) (D. Mavrodi and L. Thomashow, personal communication). Transconjugants were selected on KMB with streptomycin (100 $\mu \mathrm{g} / \mathrm{ml})$ and kanamycin $(50 \mu \mathrm{g} / \mathrm{ml})$. Colonies were patched onto $\mathrm{KMB}$ containing gentamycin $(40 \mu \mathrm{g} / \mathrm{ml})$ to screen for loss of the gentamycin resistance gene. Gentamycin-sensitive colonies were patched onto LB with 5\% sucrose to promote loss of the pFLP2Km plasmid. Sucrose-resistant colonies were patched onto KMB kanamycin plates to confirm loss of the plasmid. The resulting mutant, containing only an FRT scar at the site of the deletion, was confirmed by performing PCR across the deletion site (including all flanking sequence introduced by recombination) and sequencing the resultant product.

\section{Analysis of Pf-5 DAPG production by TLC.}

Loss of DAPG production in the phlD mutant of Pf-5 was confirmed by TLC essentially as described (Whistler et al. 2000). Wild-type and mutant cultures were grown in duplicate in nutrient broth (Difco Laboratories, Detroit) containing 2\% glucose at $27^{\circ} \mathrm{C}$. Overnight cultures were diluted to an optical density at $600 \mathrm{~nm}=0.1$ and grown for an additional $24 \mathrm{~h}$. Cultures were centrifuged $5 \mathrm{~min}$ at $5,000 \times g$. The culture supernatants were adjusted to $\mathrm{pH} \leq 2.0$ with $1 \mathrm{M} \mathrm{HCl}$ and extracted twice with $2 \mathrm{ml}$ of ethyl acetate. The organic phases were combined and dried under vacuum. Extracts were dissolved in $100 \mu \mathrm{l}$ of methanol and separated on TLC plates (silica gel 60 F254; EM Science, Gibbstown, NJ, U.S.A.) in chloroform/acetone $(9: 1, \mathrm{vol} / \mathrm{vol})$. Compounds were visualized under shortwave UV and compared with authentic standards. The $p h l D^{-}$mutant showed no detectable DAPG or monoacetylphloroglucinol production (not shown).

\section{DAPG effects on root physiology.}

Tomato seedlings were transferred to MSO plates containing various concentrations of DAPG (Toronto Research Chemicals, Toronto). The seedlings were incubated on vertically positioned DAPG plates at $26^{\circ} \mathrm{C}$, in either light (light and dark cycle of 16 and $8 \mathrm{~h}$, respectively) or darkness. After 24 and $48 \mathrm{~h}$, the plates were scanned on a Hewlett Packard DeskJet scanner and primary root lengths were measured using the APS Assess Imaging software (American Phytopathological Society Press, St. Paul, MN, U.S.A.). After 72 and 96 h, primary and lateral root lengths were determined by ruler.

To assess root growth recovery from DAPG exposure, tomato seedlings were removed from DAPG plates after 24 to $48 \mathrm{~h}$ of treatment, transferred to fresh MSO plates containing no DAPG, and incubated for an additional 24 to $48 \mathrm{~h}$. Root length was assessed before and after incubation on DAPG and after incubation on fresh plates.

Root proton secretion (Coenen et al. 2002) responses to DAPG were examined by placing tomato seedlings on MSO medium $(0.6 \%$ agar) containing various concentrations of DAPG and bromocresol purple indicator dye at $400 \mathrm{mg} \mathrm{liter}^{-1}$. Proton secretion was determined after $4 \mathrm{~h}$ by assessing color change of the bromocresol purple. 
Auxin-induced $G H 3$ promoter activity.

Hypocotyls of tobacco seedlings were excised using a scalpel under a dissecting microscope equipped with a green light and placed into individual drops of sterile distilled water on a petri dish. Hypocotyl segments were photographed with a Pixera camera attached to a Nikon SMZ1000 dissecting microscope (0.8 magnification) and segment lengths were determined using the Pixera Pro image-capturing software and measurement tool. Hypocotyls were then transferred under green light, one every $20 \mathrm{~s}$, to individual wells of a 96-well plate (Wallac, 1450-105 $8 X 12$ ) containing $100 \mu \mathrm{l}$ of a preincubation solution containing $1 \mathrm{mM}$ luciferin (Gold BioTech Inc., St. Louis) dissolved in M9 medium or phosphate buffer. Luminescence measurements for each hypocotyl segment were repeated for the indicated intervals over the time course of each experiment using a Micro Beta TriLux Luminometer (PerkinElmer, Salem, MA, U.S.A.). IAA was added from ethanolic stocks to the indicated concentrations. Ethanol concentrations within all experiments were adjusted to the same final concentration $(\leq 1 \%$, vol/ $/ \mathrm{vol})$.

In experiments characterizing the effects of DAPG on auxininduced gene expression, the preincubation solutions consisted of $10 \mathrm{mM}$ potassium phosphate $(\mathrm{pH} 6.7), 1 \mathrm{mM}$ luciferin, and various concentrations of DAPG. After $80 \mathrm{~min}$, IAA was added to each well to a final concentration of $10 \mu \mathrm{M}$, and luminescence measurements were continued. To determine the time course of DAPG effects, DAPG was omitted from the preincubation buffer and instead added $120 \mathrm{~min}$ after IAA addition. The responses of plant tissue were followed over an additional 60 to $80 \mathrm{~min}$.

To assess inhibition of auxin-inducible gene expression by supernatants of $P$. fluorescens cultures, the preincubation buffer contained $1 \mathrm{mM}$ luciferin dissolved either in 75\% M9 media or in $75 \%$ supernatants from $P$. fluorescens grown in M9 media for 4 days. After $80 \mathrm{~min}$, IAA was added to a final concentration of $10 \mu \mathrm{M}$, and luminescence counts were continued. To determine the time course of $P$. fluorescens supernatant effects, hypocotyls were preincubated in $75 \%$ M9 media containing $1 \mathrm{mM}$ luciferin and incubation solutions were replaced with $1 \mathrm{mM}$ luciferin dissolved in 75\% M9 media or 75\% P. fluorescens supernatants 120 min after IAA addition.

\section{ACKNOWLEDGMENTS}

Initial work on luciferase assay development was supported by United States Department of Agriculture (USDA) grant number 2004-35304-14995 to C. Coenen. Partial funding to support this work also came from USDA grant number 2002-35107-12271 awarded to B. McSpadden Gardener Undergraduate research grants from the Allegheny College Class of '39 Fund and the Shanbrom Fund to J. Brazelton and from the Allegheny College Faculty Development Fund to C. Coenen are gratefully acknowledged. We thank B. Müller-Röber (Universität Potsdam, Germany) for the pBin19-derived plasmid used to generate constructs for tobacco transformations and D. Mavrodi and L. Thomashow (USDA-Agricultural Research Service, Pullman, WA, U.S.A.) for the plasmid pFLP2Km used to remove the gentamycin resistance gene from the $p h l D^{-}$mutant of Pf-5. We are also indebted to C. Lundberg (Allegheny College) for editorial assistance, and to an anonymous reviewer for careful reading and thoughtful, detailed comments on an earlier version of this article.

\section{LITERATURE CITED}

Aino, M., Maekawa, Y., Mayama, S., and Kato, H. 1997. Biocontrol of bacterial wilt of tomato by producing seedlings colonized with endophytic antagonistic pseudomonads. In: Plant Growth-Promoting Rhizobacteria, Present Status and Future Prospects. A. Ogoshi, K. Kobayashi, Y. Homma, F. Kodama, N. Kondo, and S. Akino, eds. Kakashini Printing, Sapporo, Japan.

Bakker, P. A. H. M., Pieterse, C. M. J., and van Loon, L. C. 2007. Induced systemic resistance by fluorescent Pseudomonas spp. Phytopathology 97:239-243.
Bevan, M. R. 1984. Binary Agrobacterium vectors for plant transformation. Nucleic Acids Res. 12:8711-8721.

Bonsall, R. F., Weller, D. M., and Thomashow, L. S. 1997. Quantification of 2,4-diacetylphloroglucinol produced by fluorescent Pseudomonas spp. in vitro and in the rhizosphere of wheat. Appl. Environ. Microbiol. 63:951-955.

Buer, C. S., Sukumar, P., and Muday, G. K. 2006. Ethylene modulates flavonoid accumulation and gravitropic responses in roots of Arabidopsis. Plant Physiol. 140:1384-1396.

Chen, Z., Agnew, J. L., Cohen, J. D., He, P., Shan, L., Sheen, J., and Kunkel, B. N. 2007. Pseudomonas syringae type III effector AvrRpt2 alters Arabidopsis thaliana auxin physiology. PNAS 104:20131-20136.

Choi, K. H., and Schweizer, H. P. 2005. An improved method for rapid generation of unmarked Pseudomonas aeruginosa deletion mutants. BMC Microbiol. 5:30.

Coenen, C., Bierfreund, N., Lüthen, H., and Neuhaus, G. 2002. Developmental regulation of proton ATPase-dependent auxin responses in the diageotropica mutant of tomato (Lycopersicon esculentum Mill.). Physiol. Plant. 114:461-471.

Coenen, C., Christian, M., Lüthen, H., and Lomax, T. L. 2003. Cytokinin inhibits a subset of Diageotropica-dependent primary auxin responses in tomato. Plant Physiol. 131:1692-1704.

De Leij, F. A. A. M., Dixon-Hardy, J. E., and Lynch, J. M. 2002. Effect of 2,4-diacetylphlorogoucinol-producing and non-producing strains of Pseudomonas fluorescens on root development of pea seedlings in three different soil types and its effect on nodulation by Rhizobium. Biol. Fertil. Soils 35:114-121.

de Souza, J., Arnould, C., Deulvot, C., Lemanceau, P., Gianinazzi-Pearson, V., and Raaijmakers, J. M. 2003. Effect of 2,4-diacetylphloroglucinol on Pythium: Cellular responses and variation in sensitivity among propagules and species. Phytopathology 93:966-975.

Dharmasiri, N., Dharmasiri, S., and Estelle, M. 2005a. The F-box protein TIR1 is an auxin receptor. Nature 435:441-445.

Dharmasiri, N., Dharmasiri, S., Weijers, D., Lechner, E., Yamada, M., Hobbie, L., Ehrismann, J. S., Jürgens, G., and Estelle, M. 2005b. Plant development is regulated by a family of auxin receptor $\mathrm{F}$ box proteins. Dev. Cell 9:109-119.

Dubeikovsky, A. N., Mordukhova, E. A., Kochetkov, V. V., Polikarpova, F. Y., and Boronin, A. M. 1993. Growth promotion of blackcurrant softwood cuttings by recombinant strain Pseudomonas fluorescens BSP53a synthesizing an increased amount of indole-3-acetic acid. Soil Biol. Biochem. 25:1277-1281.

Dwivedi, D., and Johri, B. N. 2003. Antifungals from fluorescent pseudomonads: Biosynthesis and regulation. Curr. Sci. 85:1693-1703.

Fillatti, J. J., Kiser, J., Rose, R., and Comai, L. 1987. Efficient transfer of a glyphosate tolerance gene into tomato using a binary Agrobacterium tumefaciens vector. Biotechnology 5:726-730.

Gee, M. A., Hagen, G., and Guilfoyle, T. J. 1991. Tissue-specific and organ-specific expression of soybean auxin-responsive transcripts $\mathrm{GH} 3$ and SAURs. Plant Cell 3:419-430.

Gray, W. M., Kepinski, S., Rouse, D., Leyser, H. M. O., and Estelle, M. A. 2001. Auxin regulates SCF ${ }^{T I R 1}$-dependent degradation of the Aux/IAA proteins. Nature 414:271-276.

Haas, D., and Keel, C. 2003. Regulation of antibiotic production in rootcolonizing Pseudomonas spp. and relevance for biological control of plant disease. Annu. Rev. Phytopathol. 41:117-153.

Hagen, G., and Guilfoyle, T. J. 1985. Rapid induction of selective transcription by auxins. Mol. Cell. Biol. 5:1197-1203.

Hagen, G., Kleinschmidt, A., and Guilfoyle, T. J. 1984. Auxin-regulated gene expression in intact soybean hypocotyl and excised hypocotyl sections. Planta 162:147-153.

Hagen, G., Martin, G., Li, Y., and Guilfoyle, T. J. 1991. Auxin-induced expression of the soybean $G H 3$ promoter in transgenic tobacco plants. Plant Mol. Biol. 17:567-579.

Han, S. H., Lee, S. J., Moon, J. H., Park, K. H., Yang, K. Y., Cho, B. H. Kim, K. Y., Kim, Y. W., Lee, M. C., Anderson, A. J., and Kim, Y. C. 2006. GacS-dependent production of 2R, 3R-butanediol by Pseudomonas chlororaphis $\mathrm{O} 6$ is a major determinant for eliciting systemic resistance against Erwinia carotovora but not against Pseudomonas syringae pv. tabaci in tobacco. Mol. Plant-Microbe Interact. 19:924930.

Hoang, T. T., Karkhoff-Schweizer, R. R., Kutchma, A. J., and Schweizer, H. P. 1989. A broad-host-range Flp- $F R T$ recombination system for sitespecific excision of chromosomally-located DNA sequences: Application for isolation of unmarked Pseudomonas aeruginosa mutants. Gene 212:77-86.

Iavicoli, A., Boutet, E., Buchala, A., and Métraux, J. P. 2003. Induced systemic resistance in Arabidopsis thaliana in response to root inoculation with Pseudomonas fluorescens CHA0. Mol. Plant-Microbe Interact. 16:851-858. 
Ivanchenko, M. G., Coffeen, W. C., Lomax, T. L., and Dubrovsky, J. G. 2006. Mutations in the Diageotropica (Dgt) gene uncouple patterned cell division during lateral root initiation from proliferative cell division in the pericycle. Plant J. 46:436-447.

Jousset, A., Lara, E., Wall, L. G., and Valverde, C. 2006. Secondary metabolites help biocontrol strain Pseudomonas fluorescens CHA0 to escape protozoan grazing. Appl. Environ. Microbiol. 72:7083-7090.

Kamei, Y., and Isnansetyo, A. 2003. Lysis of methicillin-resistant Staphylococcus aureus by 2,4-diacetylphloroglucinol produced by Pseudomonas $\mathrm{sp}$. AMSN isolated from a marine alga. Int. J. Antimicrob. Agents 21:71-74.

Keel, C., Schnider, U., Maurhofer, M., Voisard, C., Laville, J., Burger, U., Wirthner, P., Haas, D., and Défago, G. 1992. Suppression of root disease by Pseudomonas fluorescens CHA0: Importance of the bacterial secondary metabolite 2,4-diacetylphloroglucinol. Mol. Plant-Microbe Interact. 5:4-13.

Kelly, M., and Bradford, K. J. 1986. Sensitivity of the diageotropica tomato mutant to auxin. Plant Physiol. 82:713-717.

Kepinski, S., and Leyser, H. M. O. 2004. Auxin-induced SCF TIR1 Aux/IAA interaction involves stable modification of the $\mathrm{SCF}^{\mathrm{TIR} 1} \mathrm{com}$ plex. PNAS 101:12381-12386.

Kepinski, S., and Leyser, O. 2005. The Arabidopsis TIR1 protein is an auxin receptor. Nature 435:446-451.

King, E. O., Ward, M. K., and Raney, D. E. 1954. Two simple media for the demonstration of pyocyanin and fluorescein. J. Lab. Clin. Med. 44:301-307.

Lee, J. S., Chang, W. K., and Evans, M. L. 1990. Effects of ethylene on the kinetics of curvature and auxin redistribution in gravistimulated roots of Zea mays. Plant Physiol. 94:1770-1775.

Loper, J. E., Kobayashi, D. Y., and Paulsen, I. T. 2007. The genomic sequence of Pseudomonas fluorescens Pf-5: Insights into biological control. Phytopathology 97:233-238.

Maurhofer, M., Keel, C., Haas, D., and Défago, G. 1995. Influence of plant species on disease suppression by Pseudomonas fluorescens strain CHA0 with enhanced antibiotic production. Plant Pathol. 44:40-50.

McClure, B. A., and Guilfoyle, T. J. 1987. Characterization of a class of small auxin-inducible soybean polyadenylated RNAs. Plant Mol. Biol. 6:611-623.

McSpadden Gardener, B. B. 2007. Diversity and ecology of biocontrol Pseudomonas in agricultural systems. Phytopathology 97:221-226.

McSpadden Gardener, B. B., Gutierrez, L. J., Joshi, R., Edema, E., and Lutton, E. 2005. Distribution and biocontrol potential of phlD ${ }^{+}$Pseudomonads in corn and soybean fields. Phytopathology 95:715-724.

Meziane, H., Van der Sluis, I., van Loon, L. C., Hofte, M., and Bakker, P. A. H. M. 2005. Determinants of Pseudomonas putida WCS358 involved in inducing systemic resistance in plants. Mol. Plant Pathol. 6:177-185.

Mito, N., and Bennett, A. B. 1995. The diageotropica mutation and synthetic auxins differentially affect the expression of auxin-regulated genes in tomato. Plant Physiol. 109:293-297.

Muday, G. K., Lomax, T. L., and Rayle, D. L. 1995. Characterization of the growth and auxin physiology of roots of the tomato mutant, diageotropica. Planta 195:548-553.

Murashige, T., and Skoog, F. 1962. A revised medium for rapid growth and bioassays with tobacco tissue cultures. Physiol. Plant. 15:473-497.
Nebenführ, A., White, T., and Lomax, T. L. 2000. The diageotropica mutation alters auxin induction of a subset of the Aux/IAA gene family of tomato. Plant Mol. Biol. 44:73-84.

Oberhänsli, T., Défago, G., and Haas, D. 1991. Indole-3-acetic acid synthesis in the biocontrol strain CHA0 of Pseudomonas fluorescens: Role of tryptophan side chain oxidase. J. Gen. Microbiol. 137:2273-2279.

Oh, K., Ivanchenko, M. G., White, T., and Lomax, T. L. 2006. The diageotropica gene of tomato encodes a cyclophilin: A novel player in auxin signaling. Planta 224:133-144.

Patten, C. L., and Glick, B. R. 2002. Role of Pseudomonas putida indoleacetic acid in development of the host plant root system. Appl. Environ. Microbiol. 68:3795-3801.

Phillips, D. A., Fox, T. C., King, M. D., Bhuvaneswari, T. V., and Teuber, L. R. 2004. Microbial products trigger amino acid exudation from plant roots. Plant Physiol. 136:2887-2894.

Reddi, T. K. K., Khudyakov, Y. P., and Borokov, A. V. 1969. Pseudomonas fluorescens strain 26-O, a producer of phytotoxic substances. Mikrobiologiya 38:909-913.

Rotenberg, D., Joshi, R., Benitez, M. S., Gutierrez Chapin, L., Camp, A., Zumpetta, C., Osborne, A., Dick, W. A., and McSpadden Gardener, B. B. 2007. Complex effects of farm management on rhizosphere colonization by native populations of phlD-containing Pseudomonas spp. and the relative contribution of those bacteria to crop stand and productivity. Phytopathology 97:756-766.

Schouten, A., van den Berg, G., Edel-Hermann, V., Steinberg, C., Gautheron, N., Alavouvette, C., De Vos, C. H., and Lemanceau, P. 2004. Defense responses of Fusarium oxysporum to 2,4-diacetylphloroglucinol, a broad-spectrum antibiotic produced by Pseudomonas fluorescens. Mol. Plant-Microbe Interact. 17:1201-1211.

Simon, R., Priefer, U. B., and Pühler, A. 1983. A broad host range mobilization system for in vivo genetic engineering: Transposon mutagenesis in gram negative bacteria. Bio/Technology 1:784-791.

Stepanova, A., Hoyt, J. M., Hamilton, A. A., and Alonso, J. M. 2005. A link between ethylene and auxin uncovered by the characterization of two root-specific ethylene-insensitive mutants in Arabidopsis. Plant Cell 17:2230-2242

Suzuki, S., He, Y., and Oyaizu, H. 2003. Indole-3-acetic acid production in Pseudomonas fluorescens HP72 and its association with suppression of creeping bentgrass brown patch. Curr. Microbiol. 47:138-143.

Vieira, J., and Messing, J. 1982. The pUC plasmids, an M13mp7-derived system for insertion mutagenesis and sequencing with universal primers. Gene 19:259-268.

Weller, D. M., Raaijmakers, J. M., McSpadden-Gardener, B. B., and Thomashow, L. S. 2002. Microbial populations responsible for specific soil suppressiveness to plant pathogens. Annu. Rev. Phytopathol. 40:309-348.

Whistler, C. A., Stockwell, V. O., and Loper, J. E. 2000. Lon protease influences antibiotic production and UV tolerance of Pseudomonas fluorescens Pf-5. Appl. Environ. Microbiol. 66:2718-2725.

Zhang, H., Kim, M. S., Krishnamachari, V., Payton, P., Sun, Y., Grimson, M., Farag, M. A., Ryu, C. M., Allen, R., Melo, I. S., and Paré, P. W. 2007. Rhizobacterial volatile emissions regulate auxin homeostasis and cell expansion in Arabidopsis. Planta 226:839-851.

Zobel, R. W. 1972. Genetics of the diageotropica mutant of the tomato. J. Hered. 63:91-97. 